\title{
Electrochemical and XPS Studies on Corrosion Behavior of Amorphous Ni-Cr-P-B alloys
}

\author{
Koji Hashimoto*, Masashi Kasaya**, Katsuhiko Asami* \\ and Tsuyoshi Masumoto* \\ *The Research Institute for Iron, Steel and Other Metals, Tohoku University
}

\begin{abstract}
Amorphous Ni-Cr-P-B alloys, which possess a high corrosion resistance and are apt to form the amorphous structure, have been prepared by rapid quenching from melts. The alloys containing chromium of 7 and 9 at. $\%$ are not corroded in $10 \% \mathrm{FeCl}_{3} \cdot 6 \mathrm{H}_{2} \mathrm{O}$ at $30^{\circ} \mathrm{C}$. Spontaneous passivation occurs on these alloys in $2 \mathrm{~N}_{2} \mathrm{SO}_{4}$ and $1 \mathrm{~N} \mathrm{HCl}$, and a critical potential for pitting is not observed on the anodic polarization curves even in $1 \mathrm{~N} \mathrm{HCl}$. Simultaneous determination of the thickness and composition of a passive film and the composition of the surface of substrate alloy directly under the passive film has been carried out by X-ray photoelectron spectroscopy. The passive film formed in $2 \mathrm{~N} \mathrm{H}_{2} \mathrm{SO}_{4}$ consists mainly of hydrated chromium oxy-hydroxide similar to those formed on corrosion-resistant crystalline alloys containing chromium and the composition of the surface of substrate alloy directly under the film is not different from that of bulk alloy. On the contrary, the composition of passive film formed in $1 \mathrm{~N} \mathrm{HCl}$ can be expressed as $\left(\mathrm{Ni}^{\mathrm{II}}{ }_{0.28} \mathrm{Cr}^{\mathrm{III}}{ }_{0.74}\right)$ $\left(\mathrm{PO}_{4}\right)_{0.74} \mathrm{O}_{x}(\mathrm{OH})_{0.52-2 x}(1.74+x) \mathrm{H}_{2} \mathrm{O}$ and hence phosphate comprises $81 \%$ of constituents of the passive film. In addition, the composition of the surface of substrate alloy directly under the film changes from that of bulk alloy. In conclusion, the amorphous $\mathrm{Ni}-\mathrm{Cr}-\mathrm{P}-\mathrm{B}$ alloys with chromium of 7 to 9 at. \% have a high corrosion resistance in strongly acidic solutions and the great resistance to pitting corrosion, but may not be always stable for a long time because of the change in alloy composition directly under the film.
\end{abstract}

\section{Introduction}

The authors ${ }^{1 \sim 4}$ ) have reported that amorphous $\mathrm{Fe}-\mathrm{Cr}-\mathrm{P}-\mathrm{C}$ and $\mathrm{Fe}-\mathrm{Cr}-\mathrm{Ni}-\mathrm{P}-\mathrm{C}$ alloys prepared by rapid quenching from liquids possess a high corrosion resistance in neutral and acidic solutions along with outstanding mechanical properties ${ }^{5 \sim 77}$. The amorphous iron-base alloys can also be prepared by adding a set of metalloid elements such as B-C, B-Si, B-P, P-Si and only B, other than $\mathrm{P}-\mathrm{C}^{8,9)}$. Among these metalloid elements, the addition of a set of $\mathbf{P}-\mathrm{C}$ is most effective in improving the corrosion resestance of amorphous ironchromium alloys ${ }^{9)}$. The difficulty in preparing a thick and wide sheet of the alloy by rapid quenching from a liquid is one of disadvantages of these iron base alloys. In this connection, Ni-Si-B system has been known to form easily the amorphous structure ${ }^{10)}$. However, a high corrosion resistance may not be expected for the amorphous alloy containing $\mathrm{Si}$ and $\mathrm{B}$ as metalloid additives.

* 2-1-1 Katahira, Sendai, 980 Japan

** Present Address: Department of Metallurgy, Muroran Institute of Technology, 27-1 Mizumoto-Cho Muroran, 050
The present study has been conducted to obtain highly corrosion resistant new amorphous nickelbase alloys containing chromium and phosphorus which can be prepared under no strict condition.

\section{Experimental Procedures}

Nickel phosphide has been prepared by the reaction of nickel powder with red phosphorus in an evacuated quartz tube during heating up to $600^{\circ} \mathrm{C}$. After melting the nickel phosphide with nickel powder, electrolytic chromium and boron powder under an argon atmosphere, alloy ingots have been prepared by sucking the melts up into a quartz tube and subsequent water-quenching. Silicon and aluminum are also added when necessary. The roller quenching method has been applied for preparing amorphous alloy sheets as follows: After remelting the ingot in a quartz tube under an argon atmosphere, a jet of liquid is blown by the pressurized argon gas between rotating two stage rollers. By this method, $100 \mu \mathrm{m}$ thick $1 \mathrm{~cm}$ wide sheets of the amorphous nickel base alloys have been prepared. The nominal compositions of amorphous alloys thus prepared are shown in Table 1. 
Table 1. Nominal compositions of amorphous nickel base alloys

\begin{tabular}{cccccc}
\hline \multicolumn{7}{c}{ Composition (at. \%) } \\
\hline $\mathrm{Ni}$ & $\mathrm{Cr}$ & $\mathrm{P}$ & $\mathrm{B}$ & $\mathrm{Si}$ & $\mathrm{Al}$ \\
\hline 77 & 3 & 15 & 5 & & \\
75 & 5 & 15 & 5 & & \\
73 & 7 & 15 & 5 & & \\
71 & 9 & 15 & 5 & & \\
70 & 9 & 15 & 5 & 1 & \\
69 & 9 & 15 & 5 & 2 & \\
67 & 9 & 15 & 5 & 4 & \\
70.5 & 9 & 15 & 5 & & 0.5 \\
\hline
\end{tabular}

An immersion test of the amorphous alloys has been performed in $10 \% \mathrm{FeCl}_{3} \cdot 6 \mathrm{H}_{2} \mathrm{O}$ at $30 \pm 1^{\circ} \mathrm{C}$. Anodic polarization curves of the alloys have been measured after polarization for $30 \mathrm{~min}$ at individual potentials in $2 \mathrm{~N} \mathrm{H}_{2} \mathrm{SO}_{4}$ and $1 \mathrm{~N} \mathrm{HCl}$. The solutions have been prepared by using reagent grade chemicals and deionized water.

For analyzing the composition of surface, X-ray photoelectron spectra of the alloy surfaces passivated for $1 \mathrm{~h}$ at various potentials have been measured by means of AEI-ES200 electron spectrometer with $\mathrm{Mg} \mathrm{K} \alpha_{1,2}$ radiation. In order to obtain fundamental data for the analysis of the composition of alloy surface, X-ray photoelectron spectra of $\mathrm{Ni}(\mathrm{OH})_{2}, \mathrm{Ni}_{2} \mathrm{O}_{3}$, emery-polished iron phosphide ( $11.1 \mathrm{wt} . \% \mathrm{P})$ and a series of $\mathrm{Fe}-\mathrm{Ni}$ alloys $(30,35,40,45,50,60,70$, at. $\% \mathrm{Ni})$ have also been measured.

\section{Results}

Critical conditions for the preparation of amorphous alloys by the roller quenching method are the revolution speed of rollers, the temperature of liquid and the pressure of argon gas for blowing. The preparation of amorphous Ni-P-B alloys is considerably easier, in particular, when chromium is added, as compared with the preparation of amorphous $\mathrm{Fe}-\mathrm{Cr}-\mathrm{P}-\mathrm{C}$ alloys.

Fig. 1 shows an effect of the addition of chromium on the corrosion rate of amorphous alloy which is estimated from the change in the weight of specimen during immersion for $168 \mathrm{~h}$ in $10 \%$ $\mathrm{FeCl}_{3} \cdot 6 \mathrm{H}_{2} \mathrm{O}$ at $30^{\circ} \mathrm{C}$. The amorphous nickel base alloys do not suffer pitting corrosion in the ferric chloride solution. With an increase in the content of chromium, the corrosion rate decreases remarkably and the alloys with chromium of 7 and 9 at. $\%$ are not practically corroded.

Fig. 2 shows potentiostatic anodic polarization curves of the amorphous alloys measured in $2 \mathrm{~N}$

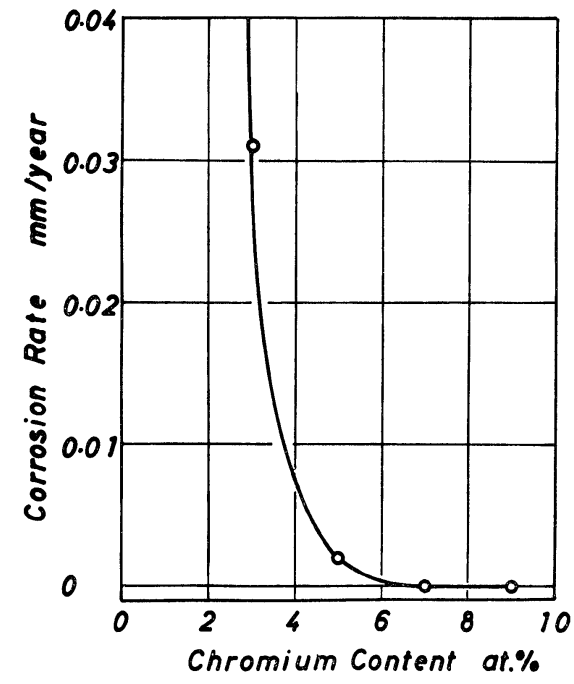

Fig. 1. Effect of the content of chromium on the corrosion rate of amorphous $\mathrm{Ni}-\mathrm{Cr}-15 \mathrm{P}-$ 5B alloys in $10 \% \mathrm{FeCl}_{3} \cdot 6 \mathrm{H}_{2} \mathrm{O}$ at $30 \pm 1^{\circ} \mathrm{C}$. The corrosion rate is estimated from the loss in weight during immersion test for $168 \mathrm{~h}$.

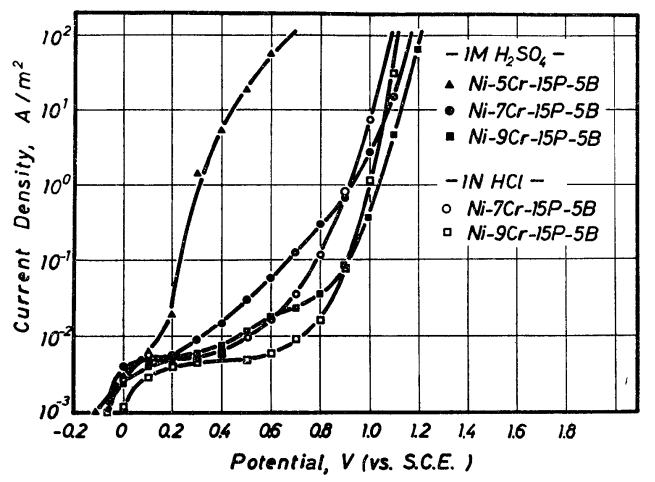

Fig. 2. Changes in potentiostatic anodic polarization curves in $2 \mathrm{~N} \mathrm{H}_{2} \mathrm{SO}_{4}$ and $1 \mathrm{~N} \mathrm{HCl}$ with the content of chromium in amorphous Ni-Cr-15P-5B alloys.

$\mathrm{H}_{2} \mathrm{SO}_{4}$ and $1 \mathrm{~N} \mathrm{HCl}$. The active state is not observed on the anodic polarization curves and spontaneous passivation occurs. Accordingly, corrosion potentials of these alloys are in the passive state of chromium. The amorphous alloys containing chromium of 7 and 9 at. \% show a wide passive region and a critical potential for pitting does not appear even in $1 \mathrm{~N} \mathrm{HCl}$. The current density in the passive region of the alloy with chromium of 9 at. $\%$ is lower than that of the alloy containing chromium of 7 at. $\%$ in both $\mathrm{HCl}$ and $\mathrm{H}_{2} \mathrm{SO}_{4}$. The current densities in the passive 


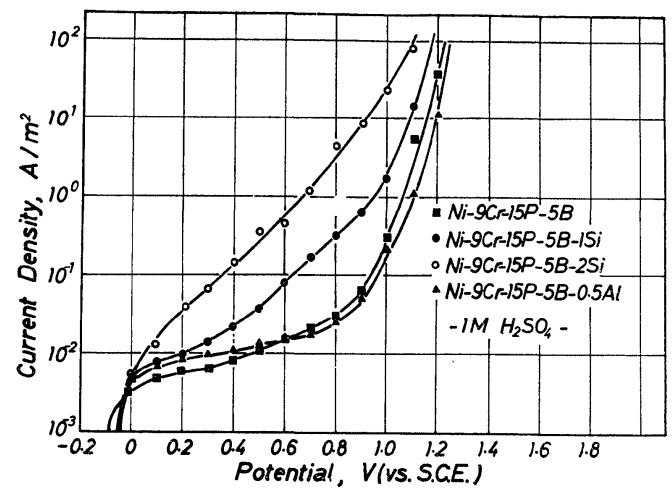

Fig. 3. Change in the potentiostatic polarization curve of amorphous $\mathrm{Ni}-9 \mathrm{Cr}-15 \mathrm{P}-5 \mathrm{~B}$ alloy in $2 \mathrm{~N}_{2} \mathrm{SO}_{4}$ with the addition of silicon and aluminum.

regions of both alloys in $\mathrm{HCl}$ are lower than those in $\mathrm{H}_{2} \mathrm{SO}_{4}$.

Fig. 3 shows effects of the addition of silicon and aluminum on the anodic polarization curves of the alloys with chromium of 9 at. \% in $2 \mathrm{~N}_{2} \mathrm{SO}_{4}$. The addition of a small amount of silicon or aluminum facilitates the formation of amorphous structure. However, the addition of silicon increases the anodic current, while the addition of aluminum does not affect significantly the anodic behavior of the alloy.

$\mathrm{X}$-ray photoelectron spectra of the alloys polarized for $1 \mathrm{~h}$ at various potentials in $1 \mathrm{~N} \mathrm{HCl}$ and $2 \mathrm{~N}$ $\mathrm{H}_{2} \mathrm{SO}_{4}$ have been measured for analyzing the composition of passive film and alloy surface directly under the passive film. Employed for the analysis are $\mathrm{Ni} 2 \mathrm{p}_{3 / 2}, \mathrm{Cr} 2 \mathrm{p}_{3 / 2}, \mathrm{P} 2 \mathrm{p}, \mathrm{O}$ 1s and $\mathrm{C}$ 1s spectra. The observable XPS spectrum of boron is practically only that of B 1s electrons, whose chemical shift between the states in the film and substrate alloy is large enough to be distinguished ${ }^{11}$. However, the binding energy of the B 1s electrons is the same as that of $\mathbf{P} 2 \mathrm{~s}$ electrons and the photoionization cross-section of the B 1s electrons is about one half of $\mathrm{P} 2 \mathrm{~s}$ electrons. Accordingly, when substituting $P$ 2s spectrum from observed spectrum after estimation of $\mathbf{P} 2 \mathrm{~s}$ spectrum from $\mathbf{P} 2 p$ spectrum measured, an appreciable $B$ 1s spectrum has not remained. This fact does not mean that boron does not exist in the films and surfaces of substrate alloys directly under the films, since boron has been found in films and substrate alloy surfaces on the amorphous $\mathrm{Fe}-\mathrm{Cr}-\mathrm{B}-\mathrm{C}$ and $\mathrm{Fe}-$ $\mathrm{Cr}-\mathrm{B}-\mathrm{Si}$ alloys passivated in $\mathrm{H}_{2} \mathrm{SO}_{4}{ }^{11}$. Because there is no method to detect boron from X-ray photoelectron spectra of the alloys containing a large amount of phosphorus, the existence of boron in the film and alloy has been disregarded for the present analysis.

The Ni $2 p_{3 / 2}$, Cr $2 p_{3 / 2}$ and $\mathrm{P} 2 p$ spectra are all superposed spectra of both oxidized state from the film and metallic state* from the substrate. Integrated intensities for metallic and oxidized states in these spectra have been separately estimated by using the same method as described elsewhere ${ }^{12}$. On contrary to the $\mathrm{O} 1 \mathrm{~s}$ spectra from $\mathrm{Fe}-\mathrm{Cr}$ alloys which reveal distinct $\mathrm{OM}$ (metal-O bond) and $\mathrm{OH}$ (metal-OH and/or metal- $\mathrm{OH}_{2}$ bond) peaks ${ }^{13)}$, a peak due to $\mathrm{PO}_{4}$ has been superimposed on OM and $\mathrm{OH}$ peaks in the broad $\mathrm{O}$ 1s spectra from the amorphous alloys and these peaks can not be separated each other. Accordingly, the total integrated intensity of $O 1$ s spectrum has been used for the present analysis.

The quantitative analysis of the surface has been performed assuming a model of three layer structure on a bulk alloy, that is, a top most layer of the homogeneous contaminant formed in the spectrometer, a middle layer of a homogeneous passive film and the bottom layer of a homogeneous alloy surface whose composition may be different from that of bulk alloy and whose thickness is infinity as compared with the escape depth of photoelectron. In this assumption, the surface structure has stepfunction-like interfaces and no concentration gradient exists within each layer. Under this assumption, a fundamental equation for photoelectron intensity in a q level of A element in a surface film can conventionally be given as follows ${ }^{12 \sim 16)}$ :

$$
\begin{aligned}
& I_{\mathrm{Aq}}{ }^{\infty}=g_{\mathrm{Aq}} \cdot \sigma_{\mathrm{Aq}}^{o x} \cdot \frac{C_{\mathrm{A}}^{o x}}{M_{\mathrm{A}}} \cdot \rho^{o x} \cdot \Lambda_{\mathrm{Aq}} \\
& \times\left\{1-\exp \left(-t / \Lambda_{\mathrm{Aq}}\right)\right\} \cdot \exp \left(-l_{\mathrm{C}} / \Lambda_{\mathrm{Aq}}\right)
\end{aligned}
$$

where $\mathrm{I}$ is the integrated intensity of photoelectron; the superscript ox corresponds to the oxidized state; $\mathrm{g}$ is the instrumental constant proportional to the kinetic energy of the photoelectron, $K_{\mathrm{Aq}}$, for the spectrometer used in this experiment $\left(g_{\mathrm{Aq}} \propto\right.$ $\left.K_{\mathrm{Aq}}\right) ; \sigma_{\mathrm{Aq}}{ }^{o x}$ is the photoionization cross-section of $\mathrm{q}$ electron level of oxidized A element; $C_{\mathrm{A}}{ }^{o x}$ is the weight fraction of $\mathrm{A}$ element in the film; $\rho^{o x}$ is the density of the film; $M_{\mathrm{A}}$ is the atomic weight of $\mathrm{A}$ element; $\Lambda_{A q}$ is the effective escape depth which is the product of the escape depth, $\lambda_{\mathrm{Aq}}$, and cosine of the angle between directions normal to specimen

* It is unknown whether a low binding energy peak of $\mathbf{P} 2 \mathrm{p}$ electrons arises from the metallic state or the anionic state. In the present paper this state of phosphorus is conveniently written as the metallic state. 
surface and of photoelectron, $\theta,\left(\Lambda_{\mathrm{Aq}}=\lambda_{\mathrm{Aq}} \cos \theta\right)$; and $\mathrm{t}$ and $l_{\mathrm{C}}$ are the thicknesses of film and contaminant layer, respectively. The escape depth, $\lambda_{\mathrm{Aq}}$, is assumed to be proportional to the square root of the kinetic energy ${ }^{17)}\left(\Lambda_{\mathrm{Aq}}=\lambda_{\mathrm{Aq}} \cos \theta \infty\right.$ $\left.\left(K_{\mathrm{Aq}}\right)^{1 / 2} \cos \theta\right)$. The estimation of the thickness of contaminant layer, $l_{\mathrm{C}}$, has been described elsewhere $^{16)}$. For simplicity, subscripts $\mathrm{Ni} 2 \mathrm{p}_{3 / 2}, \mathrm{Cr}$ $2 p_{3 / 2}, P 2 p$ and $O 1 s$, which correspond to Aq, are abbreviated as $\mathrm{Ni}, \mathrm{Cr}, \mathrm{P}$ and $\mathrm{O}$, respectively. For a surface of substrate alloy directly under the film, $t$ in equation (1) corresponds to the thickness of the surface of substrate alloy and can be approximated to be infinity as compared with $\Lambda_{\mathrm{Aq}}$. On the other hand, the thickness of passive film, $t$, acts for the extinction of photoelectron along with $l_{\mathrm{c}}$. The photoelectron intensity from the surface of substrate alloy is, therefore, expressed as:

$$
\begin{gathered}
I_{\mathrm{Aq}}{ }^{m}=g_{\mathrm{Aq}} \cdot \sigma_{\mathrm{Aq}}{ }^{m} \cdot \frac{C_{\mathrm{A}}{ }^{m}}{M_{\mathrm{A}}} \cdot \rho^{m} \cdot \Lambda_{\mathrm{Aq}} \\
\quad \times \exp \left\{-\left(t+l_{\mathrm{C}}\right) / \Lambda_{\mathrm{Aq}}\right\}
\end{gathered}
$$

where superscript $\mathrm{m}$ indicates the metallic state. The absolute values of $\sigma$ 's are hardly obtained, but the ratio of $\sigma$ 's can be estimated by using the ratio of integrated intensities of spectra measured from a standard substance whose composition is known. Accordingly, the ratios of weight fractions are employed for calculation. For instance, the ratio of weight fractions of nickel to oxygen in the passive film is espressed as;

$$
\begin{aligned}
& \frac{C_{\mathrm{Ni}}^{o x}}{C_{0}}=\frac{I_{\mathrm{Ni}}^{o x}}{I_{\mathrm{O}}} \cdot\left(\frac{K_{\mathrm{O}}}{K_{\mathrm{Ni}}}\right)^{3 / 2} \cdot \frac{\sigma_{\mathrm{O}}}{\sigma_{\mathrm{Ni}}{ }^{o x}} \cdot \frac{M_{\mathrm{Ni}}}{M_{\mathrm{O}}} \\
& \quad \times \exp l_{\mathrm{C}}\left(1 / \Lambda_{\mathrm{Ni}}-1 / \Lambda_{\mathrm{O}}\right) \frac{1-\exp \left(-t / \Lambda_{\mathrm{O}}\right)}{1-\exp \left(-t / \Lambda_{\mathrm{Ni}}\right)}
\end{aligned}
$$

Because the sum of weight fractions of constituents in a film is unity and the same is true in a substrate alloy surface, when one derives $C_{\mathrm{Cr}^{o x}} / C_{0}$, $C_{\mathrm{P}}{ }^{o x} / C_{0}$ etc. similarly to equation (3), then

$$
\begin{gathered}
\frac{C_{\mathrm{Ni}}^{o x}}{C_{\mathrm{O}}}+\frac{C_{\mathrm{Cr}^{o x}}}{C_{\mathrm{o}}}+\frac{C_{\mathrm{P}}^{o x}}{C_{\mathrm{O}}}+\frac{C_{\mathrm{o}}}{C_{\mathrm{O}}}=\frac{1}{C_{\mathrm{o}}} \\
=\frac{C_{\mathrm{Ni}}{ }^{m}}{C_{\mathrm{O}}}+\frac{C_{\mathrm{Cr}}{ }^{m}}{C_{\mathrm{o}}}+\frac{C_{\mathrm{P}}{ }^{m}}{C_{\mathrm{o}}}
\end{gathered}
$$

If all values other than the thickness of film, $t$, and weight fractions, $C$ 's, are known in all the equations of $\boldsymbol{C}_{\mathrm{A}} / \boldsymbol{C}_{\mathrm{O}}$ 's, $t$ can be estimated by solving equation (4) and subsequently the weight fractions of elements, $C$ 's, can be obtained. In order to solve equation (4) the ratios of $\sigma$ 's must be known. As reported previously ${ }^{13)}, \sigma_{\mathrm{Cr}}{ }^{o x} / \sigma_{0}={\sigma_{\mathrm{Cr}}}^{m} / \sigma_{\mathrm{O}}=1.71$.
However, for $\sigma_{\mathrm{Ni}}{ }^{m} / \sigma_{\mathrm{O}}$ and $\sigma_{\mathrm{P}} / \sigma_{\mathrm{O}}$ different values have been reported considering peak hights or integrated intensisties with or without satellites ${ }^{18 \sim 23)}$. These ratios must, therefore, be determined depending upon the way of evaluation of integrated intensities. The ratio of ${\sigma_{\mathrm{Ni}}}^{\circ x} / \sigma_{\mathrm{O}}$ has been determined by using standard substances $\mathrm{Ni}(\mathrm{OH})_{2}$ and $\mathrm{Ni}_{2} \mathrm{O}_{3}$ and is 1.53. The ratio of $\sigma_{\mathrm{P}} / \sigma_{\mathrm{O}}$ is estimated as follows: $\mathrm{X}$-ray photoelectron spectra of emery-polished iron phosphide, in which $C_{P}{ }^{m}$ is 0.111 , have been measured. Because no satellites appear in both P 2p spectra of phosphorus in the film and substrate, $\sigma_{\mathrm{P}}{ }^{m}$ equals $\sigma_{\mathrm{P}}{ }^{o x}$ if one takes not peak hights but integrated intensities of $I_{\mathrm{P}}{ }^{m}$ and $I_{\mathrm{P}}{ }^{o x}$. The ratio of $\sigma_{\mathrm{Fe}}{ }^{m} / \sigma_{\mathrm{P}}{ }^{m}$ is expressed as;

$$
\begin{aligned}
\frac{\sigma_{\mathrm{P}}{ }^{m}}{\sigma_{\mathrm{Fe}}{ }^{m}} & =\frac{I_{\mathrm{P}}{ }^{m}}{I_{\mathrm{Fe}}{ }^{m}} \cdot\left(\frac{K_{\mathrm{Fe}}}{K_{\mathrm{P}}}\right)^{3 / 2} \cdot \frac{C_{\mathrm{Fe}}{ }^{m}}{C_{\mathrm{P}}{ }^{m}} \cdot \frac{M_{\mathrm{P}}}{M_{\mathrm{Fe}}} \\
& \times \exp \left\{\left(t+l_{\mathrm{C}}\right) \cdot\left(\frac{1}{\Lambda_{\mathrm{P}}}-\frac{1}{\Lambda_{\mathrm{Fe}}}\right)\right\}
\end{aligned}
$$

The ratio of ${\sigma_{\mathrm{P}}}^{m} / \sigma_{\mathrm{Fe}}{ }^{m}$ has been estimated as a first approximation substituting 0.111 for $C_{\mathrm{P}}{ }^{m}, 0.889$ for $C_{\mathrm{Fe}}{ }^{m}$ and arbitrary value for $t$ in equation (5). Multiplication of this ratio by known ratio of $\sigma_{\mathrm{Fe}}{ }^{m} / \sigma_{\mathrm{O}}{ }^{13)}$ gives the value of ${\sigma_{\mathrm{P}}}^{m} / \sigma_{\mathrm{O}}=\sigma_{\mathrm{P}}{ }^{o x} / \sigma_{\mathrm{O}}$ as a first approximation. The equation for iron phosphide similar to equation (4) is;

$$
\frac{C_{\mathrm{Fe}}^{o x}}{C_{\mathrm{O}}}+\frac{C_{\mathrm{P}}{ }^{o x}}{C_{0}}+1-\frac{C_{\mathrm{Fe}}{ }^{m}}{C_{\mathrm{O}}}-\frac{C_{\mathrm{P}}{ }^{m}}{C_{\mathrm{O}}}=0
$$

Equation (6) can be solved by using this $\sigma_{P} / \sigma_{O}$ and known $\sigma_{\mathrm{Fe}}{ }^{o x} / \sigma_{\mathrm{O}}{ }^{13)}$ and $\sigma_{\mathrm{Fe}}{ }^{m} / \sigma_{\mathrm{O}}$. Hence, the thickness of the film on the iron phosphide, $t$, has been obtained as a second approximation. Substituting this value of $t$ in equation (5) the ratio of $\sigma_{\mathrm{P}}{ }^{m} / \sigma_{\mathrm{Fe}}{ }^{m}$ has been again estimated as a second approximation. By repetition of this procedure until $C_{P}{ }^{m}$ obtained by solving equation (6) becomes equal to 0.111 , the reliable value of $\sigma_{\mathrm{P}} / \sigma_{\mathrm{O}}$ has been estimated and is 0.786. The ratio of $\sigma_{\mathrm{Ni}}{ }^{m} / \sigma_{\mathrm{O}}$ has been estimated by the least-squares method after applying similar procedure for a series of $\mathrm{Fe}-\mathrm{Ni}$ alloys and is 8.59.

Substituting the ratios of $\sigma$ 's and of observed integrated intensities in equation (4), the thickness and composition of the passive film and the composition of the surface of substrate alloy directly under the passive film have been estimated simultaneously. Analytical results are shown in Figs. 4-9. Figs. 4 and 5 show the cationic fractions in the passive film and the atomic fractions in the surface of substrate alloy on the amorphous $\mathrm{Ni}$ 9Cr-15P-5B alloy polarized for $1 \mathrm{~h}$ at various potentials in $1 \mathrm{~N} \mathrm{HCl}$. Included for comparison in the figures are the atomic fractions in the bulk 


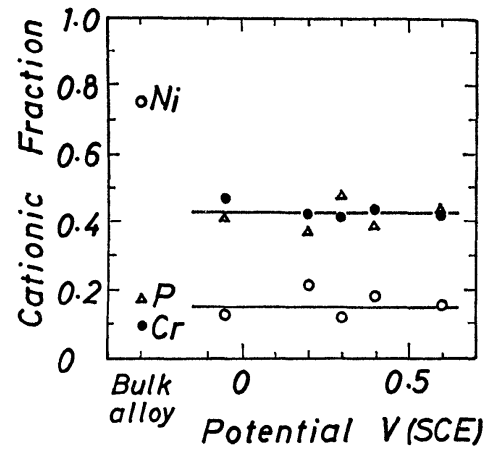

Fig. 4. Cationic fractions in the passive films formed on amorphous $\mathrm{Ni}-9 \mathrm{Cr}-15 \mathrm{P}-5 \mathrm{~B}$ alloy polarized for $1 \mathrm{~h}$ at various potentials in $1 \mathrm{~N} \mathrm{HCl}$. The atomic fractions in the bulk alloy are included for comparison

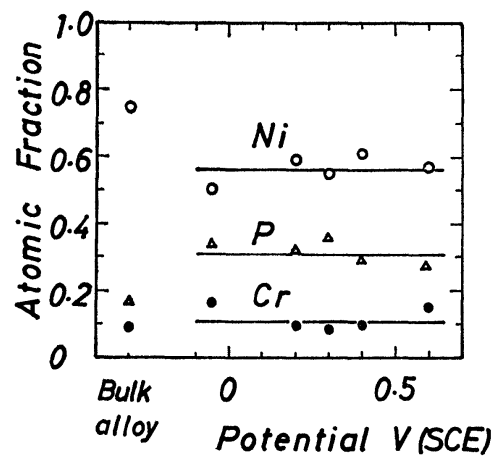

Fig. 5. Atomic fractions in the surfaces of substrate alloy directly under the passive films whose cationic fractions are shown in Fig. 4. The atomic fractions in the bluk alloy are included for comparison.

alloy. The compositions of the passive film and surface of substrate alloy do not largely change with the polarization potential. Preferential dissolution of nickel results in significant enrichments of chromium and phosphorus in the passive film. On the other hand, in the surface of substrate alloy directly under the passive film the deficiency of nickel and the enrichment of phosphorus take place, while the content of chromium remains approximately the same as that of the bulk alloy.

Figs. 6 and 7 show the cationic fractions in the passive film and the atomic fractions in the surface of substrate alloy directly under the passive film on the amorphous $\mathrm{Ni}-7 \mathrm{Cr}-15 \mathrm{P}-5 \mathrm{~B}$ alloy polarized for $1 \mathrm{~h}$ at various potentials in $2 \mathrm{~N} \mathrm{H}_{2} \mathrm{SO}_{4}$. Included for comparison in the figures are the atomic fractions in the bulk alloy. Figs. 6 and 7 also show the cationic fractions in the surface of substrate alloy directly under the surface film on the

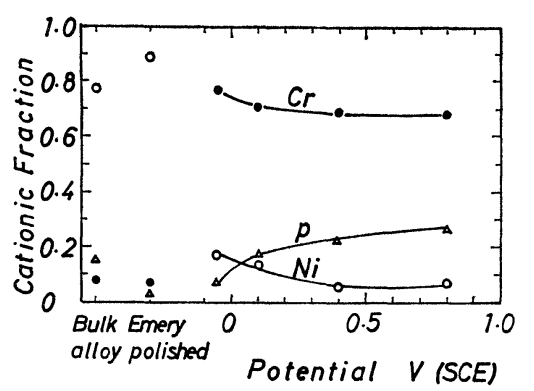

Fig. 6. Cationic fractions in the passive films formed on amorphous $\mathrm{Ni}-7 \mathrm{Cr}-15 \mathrm{P}-5 \mathrm{~B}$ alloy polarized for $1 \mathrm{~h}$ at various potentials in $2 \mathrm{~N} \mathrm{H}_{2} \mathrm{SO}_{4}$. Included for comparison are the atomic fractions in the bulk alloy and the cationic fractions in the surface film formed during emery-polishing in trichloroethylene. The emery-polishing has been carried out prior to the polarization treatment for all specimens.

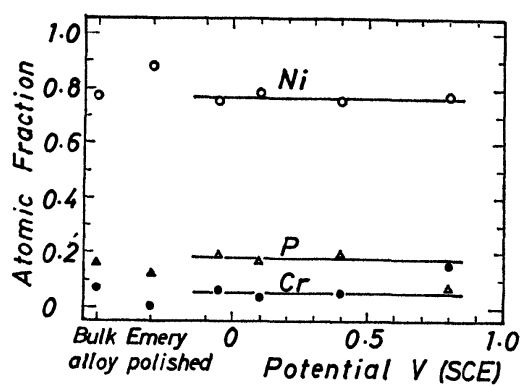

Fig. 7. Atomic fractions in the surface of substrate alloy directly under the films whose cationic fractions are shown in Fig. 6.

alloy emery-polished in trichloroethylene which is the starting material for polarization treatment. Preferential dissolution brings about again the enrichment of chromium in the passive film. The composition of bulk alloy is almost maintained in the surface of substrate alloy directly under the passive film after passivation treatment. The compositions of the film and surface of substrate alloy after emery-polishing are considerably different from the composition of the bulk alloy. However, during the passivation treatment the surface film formed by emery-polishing has been dissolved in the solution and the composition of the surface of substrate alloy returns to that of the bulk alloy.

Fig. 8 shows the atomic fractions of oxygens in the passive films formed on the amorphous $\mathrm{Ni}$ 9Cr-15P-5B alloy in $1 \mathrm{~N} \mathrm{HCl}$ and on the amorphous $\mathrm{Ni}-7 \mathrm{Cr}-15 \mathrm{P}-5 \mathrm{~B}$ alloy in $2 \mathrm{~N}_{2} \mathrm{SO}_{4}$. The concentrations of oxygens in the passive films are 


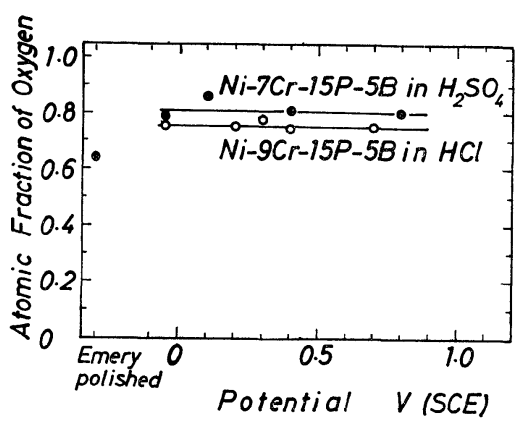

Fig. 8. Atomic fraction of oxygen in the passive films formed by polarization for $1 \mathrm{~h}$ at various potentials on amorphous $\mathrm{Ni}$ 9Cr-15P-5B alloy in $1 \mathrm{~N} \mathrm{HCl}$ and on amorphous $\mathrm{Ni}-7 \mathrm{Cr}-15 \mathrm{P}-5 \mathrm{~B}$ alloy in $2 \mathrm{~N}$ $\mathrm{H}_{2} \mathrm{SO}_{4}$. The atomic fraction of oxygen in the surface film formed on the latter alloy during emery-polishing in trichloroethylene is also written in the figure.

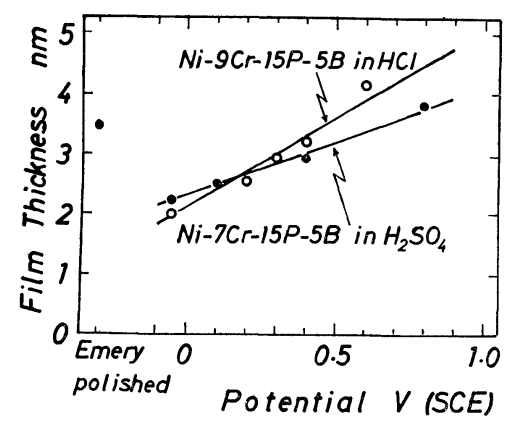

Fig. 9. Changes in the thickness of passive films formed by polarization for $1 \mathrm{~h}$ on amorphous Ni-9Cr-15P-5B alloy in $1 \mathrm{~N} \mathrm{HCl}$ and on amorphous $\mathrm{Ni}-7 \mathrm{Cr}-15 \mathrm{P}-5 \mathrm{~B}$ alloy in $2 \mathrm{~N}_{2} \mathrm{SO}_{4}$ as a function of polarization potential. The thickness of the surface film formed on the latter alloy during emery-polishing in trichloroethylene is included for comparison.

almost independent of polarization potentials and the passive film formed in $2 \mathrm{~N} \mathrm{H}_{2} \mathrm{SO}_{4}$ contains higher amount of oxygen than that formed in $1 \mathrm{~N}$ $\mathrm{HCl}$. Fig. 9 shows changes in thicknesses of the films formed on the amorphous $\mathrm{Fe}-9 \mathrm{Cr}-15 \mathrm{P}-5 \mathrm{~B}$ alloy in $1 \mathrm{~N} \mathrm{HCl}$ and on the amorphous $\mathrm{Fe}-7 \mathrm{Cr}-$ 15P-5B alloy in $2 \mathrm{~N} \mathrm{H}_{2} \mathrm{SO}_{4}$ as a function of polarization potential. The thicknesses of the passive films formed in both solutions increase linearly with the increase in the potential. The gradient of the increase in the thickness with the potential is higher in $1 \mathrm{~N} \mathrm{HCl}$ than in $2 \mathrm{~N} \mathrm{H}_{2} \mathrm{SO}_{4}$.

\section{Discussion}

The amorphous structure can be formed for the $\mathrm{Ni}-\mathrm{Cr}-\mathrm{P}-\mathrm{B}$ alloys under considerably mild condition as compared with the amorphous $\mathrm{Fe}-\mathrm{Cr}-\mathrm{P}-\mathrm{C}$ alloys. The addition of chromium facilitates the formation of amorphous structure and ensures a high corrosion resistance to the alloys. Some of characteristics of the amorphous alloys containing a large amount of phosphorus along with chromium are no appearance of critical pitting potential on anodic polarization curves even in $1 \mathrm{~N} \mathrm{HCl}$ and spontaneous passivation of the alloys in acidic solutions with and without chloride ions ${ }^{9,24)}$. The corrosion rates of the alloys in ferric chloride solution are remarkably low. Consequently, the amorphous Ni-Cr-P-B alloys have fairly high corrosion resistance and are immune to pitting corrosion. Phosphorus may be responsible for accelerating passivation through the enrichment of chromium due to reduction of phosphorus to hydrogen phosphide at the potential lower than $-0.3 \mathrm{~V}$ (S. C. E.) where chromium and nickel are oxydized $^{24)}$.

The average composition of the passive film

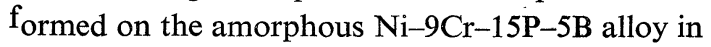
$1 \mathrm{~N} \mathrm{HCl}$ is estimated from Figs. 4, 5 and 8 and is expressed as:

$$
\begin{array}{r}
\left(\mathrm{Ni}^{\mathrm{II}}{ }_{0.26} \mathrm{Cr}^{\mathrm{III}}{ }_{0.74}\right)\left(\mathrm{PO}_{4}\right)_{0.74} \mathrm{O}_{x}(\mathrm{OH})_{0.52-2 x}(1.74+x) \\
\mathrm{H}_{2} \mathrm{O} .
\end{array}
$$

About $81 \%$ of constituents of the passive film formed in $1 \mathrm{~N} \mathrm{HCl}$ is phosphate and the remainder is oxy-hydroxide. When protective passive films are formed, the compositions of bulk alloys have been maintained in the surface of substrate alloys directly under the passive films ${ }^{25,26)}$. However, this is not the case for the alloy polarized in aggressive hydrochloric acid. On the other hand, the composition of the surface of substrate alloy under the passive film on the amorphous $\mathrm{Ni}-7 \mathrm{Cr}-15 \mathrm{P}$ $5 \mathrm{~B}$ alloy in $2 \mathrm{~N}_{2} \mathrm{SO}_{4}$ remains unchanged from that of the bulk alloy. The composition of the passive film formed on the alloy at $0.8 \mathrm{~V}$ in $2 \mathrm{~N}$ $\mathrm{H}_{2} \mathrm{SO}_{4}$ can be written from Figs. 6, 7 and 8 as:

$$
\left(\mathrm{Ni}^{\mathrm{II}}{ }_{0.08} \mathrm{Cr}^{\mathrm{III}}{ }_{0.92}\right)\left(\mathrm{PO}_{4}\right)_{0.37} \mathrm{O}_{x}(\mathrm{OH})_{1.81-2 x}(2.78+\mathrm{x})
$$

$\mathrm{H}_{2} \mathrm{O}$.

Oxy-hydroxide comprises about $62 \%$ of the constituents in the passive film formed in $2 \mathrm{~N}_{2} \mathrm{SO}_{4}$ at $0.8 \mathrm{~V}$ where the content of phosphorus in the film is the highest among the films formed in $2 \mathrm{~N} \mathrm{H}_{2} \mathrm{SO}_{4}$. The passive films formed in both solutions are amorphous, and hydroxyl groups, phosphate ions and divalent oxygen ions will not be localized but 
distributed in disorder.

The enrichment of chromium in passive films has been found on many corrosion resistant iron-base alloys containing chromium ${ }^{4,24 \sim 30)}$, but the magnitude of $\mathrm{t}$ e enrichment on the amorphous alloys is remarkably high as compared with crystalline $\mathrm{Fe}-$ $\mathrm{Cr}$ alloys ${ }^{25)}$. Some of the present authors ${ }^{4,25,26)}$ have reported that the corrosion resistant passive films formed on alloys containing chromium consist mainly of hydrated chromium oxy-hydroxide. The passive film formed on the amorphous $\mathrm{Ni}-7 \mathrm{Cr}$ 15P-5B alloy in $2 \mathrm{~N} \mathrm{H}_{2} \mathrm{SO}_{4}$ is also composed mainly of hydrated chromium oxy-hydroxide but contains some amounts of phosphate. In $1 \mathrm{~N}$ $\mathrm{HCl}$ which is more aggressive than $2 \mathrm{~N} \mathrm{H}_{2} \mathrm{SO}_{4}$, the passive film on the nickel-base alloy consists mainly of phosphate and the composition of the surface of substrate alloy directly under the passive film is distinct from that of the bulk alloy. As reported previously ${ }^{4}$, chromium and phosphorus contained in the passive film formed on the amorphous $\mathrm{Fe}-10 \mathrm{Cr}-13 \mathrm{P}-7 \mathrm{C}$ alloy in $1 \mathrm{~N} \mathrm{HCl}$ are $95 \%$ and only $3 \%$, respectively, and hence the passive film consists exclusively of a hydrated chromium oxy-hydroxide. The passive film composed mainly of chromium oxy-hydroxide has also been formed in $1 \mathrm{~N} \mathrm{HCl}$ on the amorphous $\mathrm{Fe}-3 \mathrm{Cr}-2 \mathrm{Mo}-13 \mathrm{P}-$ $7 \mathrm{C}$ alloy whose chromium content is only 3 at. \% and when the content of phosphate in the passive film increases the protection of the film against dissolution lowers ${ }^{24)}$. In the present study the main constituent of passive film formed in the aggressive hydrochloric acid is phosphate although the thickness of the film is comparable to ordinary passive films ${ }^{24 \sim 26)}$. The amount of bound water, which is also anticipated to be important in increasing the protection of the passive film, is lower in the passive film formed in $1 \mathrm{~N} \mathrm{HCl}$ than that in the film formed in $2 \mathrm{~N}_{2} \mathrm{SO}_{4}$.

As reported previously ${ }^{24,25)}$, the scatter of analytical result is small when highly protective passive films have been formed. However, the analytical results shown in Figs. 49 exhibit some scatter indicating incomplete protection of the passive films. The incomplete protection may result partly from the existence of a large amount of boron in the alloy which is harmful for improving the corrosion resistance of amorphous alloys ${ }^{8,91}$. The high corrosion resistance of amorphous $\mathrm{Fe}$ $\mathrm{Cr}-\mathrm{P}-\mathrm{C}$ alloys has been attributed in part to rapid passivation through an enrichment of chromium due to high reactivity of the alloys without films ${ }^{31}$. Accordingly, the formation of hydrated chromium oxy-hydroxide film on the amorphous nickel base alloys may be decelerated by nickel which retards active dissolution of alloys and polarization for $1 \mathrm{~h}$ may not be long enough to produce the stable passive film on the amorphous nickel base alloys.

In conclusion, the Ni-Cr-P-B alloys have high corrosion resistance in strongly acidic solutions and are immune to pitting corrosion. It is, however, vague whether the alloys are stable for long time or not in $\mathrm{HCl}$ because the change in the alloy composition takes place directly under the passive film.

(Received April 23, 1977)

\section{References}

1) M. Naka, K. Hashimoto and T. Masumoto: $J$. Japan Inst. Metals, 38, 835 (1974).

2) M. Naka, K. Hashimoto and T. Masumoto: Corrosion, 32, 146 (1976).

3) K. Hashimoto, K. Osada, T. Masumoto and S. Shimodaira: Corr. Sci., 16, 71 (1976).

4) K. Asami, K. Hashimoto, T. Masumoto and S. Shimodaira: Corr. Sci., 16, 909 (1976).

5) T. Masumoto and H. Kimura: J. Japan Inst. Metals, 39, 133 (1975).

6) T. Masumoto and R. Maddin: Mater. Sci. Eng., 19, 1 (1975).

7) H. Kimura and T. Masumoto: Script. Met., 9, 211 (1975).

8) M. Naka, K. Hashimoto and T. Masumoto: Sci. Rep., Res. Inst. Tohoku University, A26, 283 (1977).

9) M. Naka, K. Hashimoto and T. Masumoto: to be published in J. Noncryst. Solid.

10) T. Masumoto, H. Kimura, A. Inoue and $Y$. Waseda: Mater. Sci. Eng., 23, 141 (1976).

11) K. Hashimoto, M. Naka, K. Asami and T. Masumoto: to be published.

12) K. Asami, K. Hashimoto and S. Shimodaira: J. Japan Inst. Metals, 40, 438 (1976).

13) K. Asami and K. Hashimoto and S. Shimodaira: Corr. Sci., 17, (1977).

14) T. A. Carlson and G. E. McGuire: J. Electron Spectrosc., 1, 161 (1972/73).

15) C. S. Fadley. R. Baird, W. Sickhaus, J. Novakov and S. L. Bergström: J. Electron Spectrosc., 4, 93 (1974).

16) K. Asami and K. Hashimoto: Corr. Sci., 17, (1977).

17) M. Klasson, J. Hedman, A. Berndttson, R. Nilson, C. Nordling and P. Melnik: Physica Scripta, 5, 93 (1972).

18) J. H. Scofield: J. Electron Spectrosc., 8, 129 (1976).

19) C. D. Wagner: Anal. Chem., 44, 1050 (1972).

20) C. K. Jørgensen and H. Berthou: Trans. Faraday Discuss., 54, 269 (1972). 
21) H. Berthou and C. K. Jørgensen: Anal. Chem., 47, 482 (1975).

22) V. I. Nefedov, N. P. Sergushin, I. M. Band and M. B. Trzhakovskaja: J. Electron Spectrosc., 2, 283 (1973).

23) V. I. Nefedov, N. P. Sergushin and Y. V. Salyn: J. Electron Spectrosc., 7, 175 (1975).

24) K. Hashimoto, J. Noguchi, K. Asami and T. Masumoto: Presented at the Spring Meeting of Japan Society of Corrosion Engineering, (1977).

25) K. Asami, K. Hashimoto and S. Shimodaira: Corr. Sci., 17, (1977).

26) K. Teramoto, K. Asami and K. Hashimoto:
Presented at the Spring Meeting of Japan Society of Corrosion Engineering, (1976).

27) K. Hashimoto, T. Masumoto and S. Shimodaira: "Passivity and Its Breakdown on Iron and Iron Base Alloys", Proc. the U. S. A.-Japan Seminar, Honolulu, (1975), Ed. by R. W. Staehle and H. Okada, p. 34, National Association of Corrosion Engineers, Houston (1976).

28) A. E. Yaniv, J. B. Lumsden and R. W. Staehle: ibid., p. 72.

29) H. Okada, H. Ogawa, I. Itoh and H. Omata: ibid., p. 82.

30) K. Sugimoto and Y. Sawada: Corr. Sci. 17, 425 (1977). 